\title{
Erratum to: Modelling foetal exposure to maternal smoking using hepatoblasts from pluripotent stem cells
}

\author{
Baltasar Lucendo-Villarin ${ }^{1}$ Panagiotis Filis ${ }^{2} \cdot$ Madeleine J. Swortwood $^{3} \cdot$ \\ Marilyn A. Huestis ${ }^{4} \cdot$ Jose Meseguer-Ripolles $^{1} \cdot$ Kate Cameron $^{1} \cdot$ John P. Iredale $^{5}$. \\ Peter J. O'Shaughnessy ${ }^{6} \cdot$ Paul A. Fowler $^{2} \cdot$ David C. Hay $^{1}$ (D)
}

Published online: 3 October 2017

(c) Springer-Verlag GmbH Germany 2017

\section{Erratum to: Arch Toxicol \\ DOI 10.1007/s00204-017-1983-0}

This article contains a mistake in the author list which should read:

Baltasar Lucendo-Villarin, Panagiotis Filis, Madeleine J. Swortwood, Marilyn A. Huestis, Jose Meseguer-Ripolles, Kate Cameron, John P. Iredale, Peter J. O’Shaughnessy, Paul A. Fowler, David C. Hay

The author's name was also corrected in the original article.
During manuscript proofing, the following sentence was not deleted in the section "Results" at the end of the paragraph "Determining the sex differences in hepatocyte biology following exposure to cotinine and PAHs" may confuse the readers and therefore needs to be deleted: "Both male and female hepatocytes responded in a similar fashion to cotinine, whereas male hepatocyte function was more sensitive to chrysene, fluorene and naphthalene than female hepatocytes". The publishers are sorry for any inconvenience caused.

The online version of the original article can be found under doi:10.1007/s00204-017-1983-0.

David C. Hay

davehay@talktalk.net

1 Medical Research Council Centre for Regenerative

Medicine, University of Edinburgh, 5 Little France Drive,

Edinburgh EH16 4UU, Scotland, UK

2 Institute of Medical Sciences, University of Aberdeen, Foresterhill, Aberdeen AB25 2ZD, UK

3 Department of Forensic Science, College of Criminal Justice, Sam Houston State University, Huntsville, TX, USA

4 University of Maryland School of Medicine, Baltimore, MD 21201, USA

5 University of Bristol, Senate House, Tyndall Avenue, Bristol BS8 1TH, UK

6 Institute of Biodiversity, Animal Health and Comparative Medicine, University of Glasgow, Glasgow G61 1QH, UK 